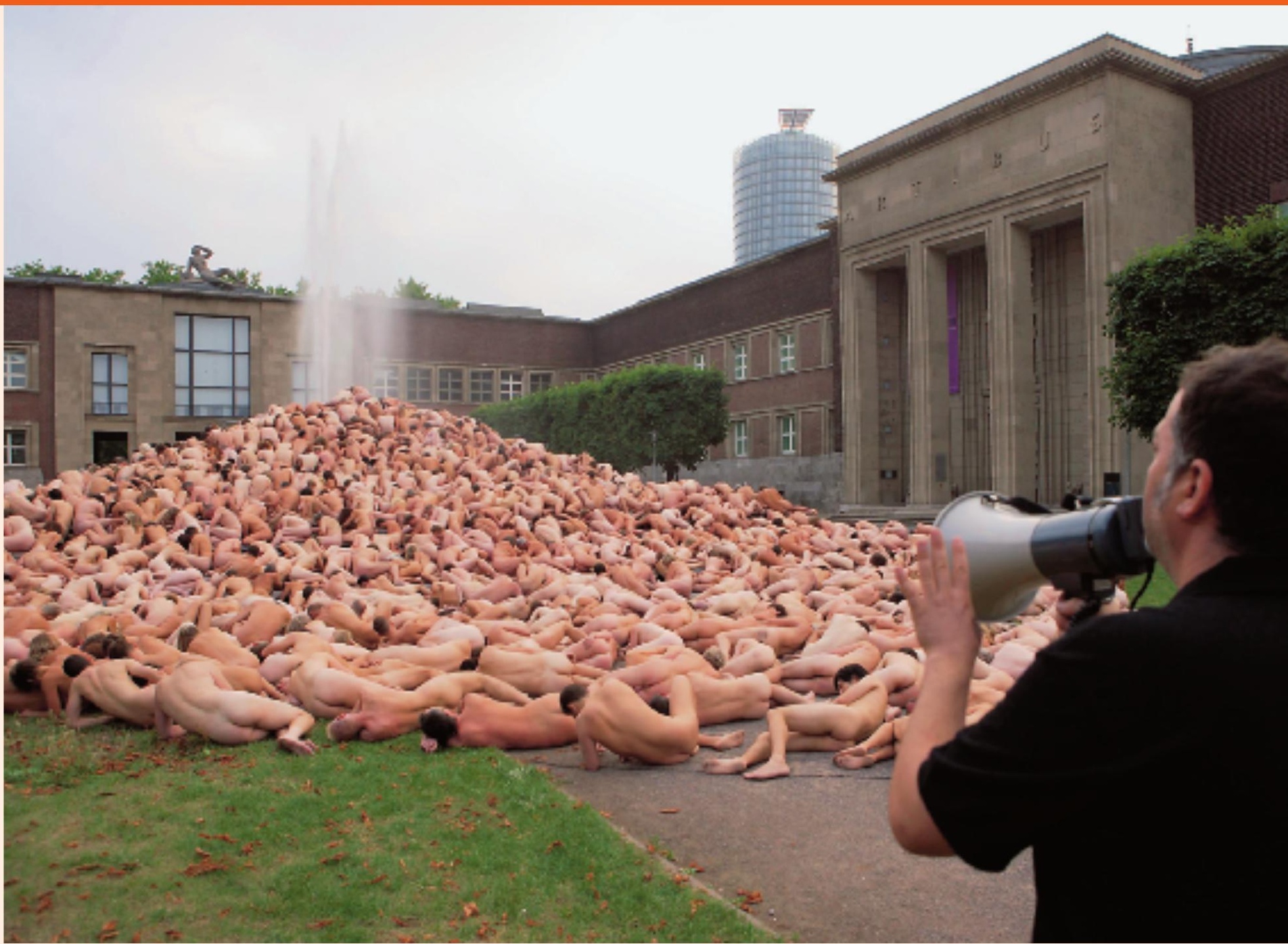

Copyright: museum kunst palast, Düsseldorf. Photo: Stefan Arendt.

\title{
Der Mensch ist nur im Singular
}

Erhard Taverna

Das eigene Hemd ist uns am nächsten, sagt man, oder Kleider machen Leute. Was geschieht mit dem Betrachter, wenn plötzlich Hunderte ihre Hüllen fallen lassen, was empfinden die Akteure? Es gibt diese Experimente, sorgfältig komponierte Auftritte, jenseits gewohnter Rituale. Eine sprachlose Gegenwelt.

Sie posieren immer im Freien, auf öffentlichen Plätzen, auf Tribünen und am Strand. Sie stehen dicht an dicht auf frostigen Alleen oder liegen mit hochgestreckten Beinen zwischen gestapelten Containern. Wenn es Spencer Tunick (geb. 1967) für nötig hält, harren Tausende bei Sturm und eisigen Temperaturen aus, bis der Meister sie endlich ablichtet. Der amerikanische Fotograf begann 1992 mit seinen Kompositionen in den Strassen New Yorks und ist heute in fast allen grossen Ausstellungen vertreten. Die Menschen auf seinen Bildern sind ausnahmslos nackt, Männer und Frauen, Alte und Junge, Dicke und Dünne. Hässliche und Schöne. Freiwillige aus vielen Ländern, die sich jährlich unentgeltlich ausziehen, um in Gruppen oder unübersehbaren Mengen Modell zu stehen. Man könnte Tunick als einen Antipoden von Christo bezeichnen. Der eine verhüllt, der andere entkleidet. Beide verfremden visuelle Konventionen, indem sie das Gewohnte neuartig inszenieren. Für uns alle, die sich immer bedeckt halten, geht von Nackten in grosser Zahl eine zwiespältige Wirkung aus. Die Intimität des einzelnen löst sich in der Vielzahl auf, Mann und Frau verschwinden in der Anonymität. Eine grosse Menge entblösster Körper strapaziert unsere 
Sehgewohnheiten. Das eine ist die Inszenierung in einer Umgebung, wo nackte Haut normalerweise nicht vorkommt, und das andere sind die unheilvollen Vorbilder. Diese mehr oder weniger bewussten Vorstellungen erinnern an Tod, Verdammnis und Gewalt, an Massengräber, Gaskammern und jüngstes Gericht. Die überlieferte Regie bleibt konstant: Die Guten verhüllen lange Gewänder, die Bösen stürzen nackt in die Hölle. Den Tätern in Fell und Hörnern oder in Uniformen und Stiefeln stehen die verurteilten Opfer in schutzloser Blösse gegenüber.

Spencer Tunick und mit anderen Stilmitteln Vanessa Beecroft (geb. 1969) gehören zu einer Generation Künstler, die geschickt eine lange einheimische Bildtradition unterlaufen. Denn Nacktheit ist seit dem Sündenfall unmoralisch oder zumindest peinlich. Das Bocksfüssige und Fischschwänzige wurde missioniert und mit ihm das bacchantische Getümmel der Antike in einen Sündenpfuhl verwandelt. In Hieronymus Boschs «Garten der Lüste» wimmelt es von beschäftigten nackten Figuren, die sich blass und traumwandlerisch zu den seltsamsten Spielen vereinigen, ohne dass dabei auch nur ein Hauch von Lust oder Freude aufkäme. Nur im Rückgriff auf die alten mythologischen Verkleidungen konnten die späteren Maler ihre Landschaften mit Nackedeien ausstaffieren.

Die Aufmärsche von Tunick und Beecroft erinnern daran, dass wir zum natürlichsten Körperzustand keine wertfreie oder ungestörte
Beziehung haben. Ist der Zugang medizinisch, wird alles abgedeckt, was nicht untersucht oder behandelt werden soll. Ist er voyeuristisch oder pornografisch, bleibt er genital fixiert. Die Künste betonen das Porträt, das Paar oder die Gruppe. Es ist, als wäre unser Sehfeld eingeschränkt, als könnten wir gleichzeitig nur wenige Exemplare unserer nackten Gattung mit Wohlgefallen in den Blick bekommen. Was quantitativ darüber hinausgeht, macht uns ratlos und unbehaglich, denn das vervielfältigte Geschlecht verwandelt uns in ein Neutrum, in einen Niemand. Wenn Kleider Leute machen, dann sind wir ohne sie kaum existent, nicht auf die Dauer und schon gar nicht in einer Menge. Als Teil einer biologischen Masse finden wir uns auf gleicher Stufe wie Ameisen oder ein Schwarm Fische. Abstraktes Rädchen im textilfreien Getriebe. In der Horde oder im Rudel erkennen wir uns besser, das entspricht wohl der Stammesgeschichte. Doch für den vorurteilslosen Durchblick müssten man(n) oder frau an einer dieser Veranstaltungen teilnehmen. In Düsseldorf, wie diesen Sommer, mit 839 weiteren Schwestern und Brüdern, die hüllenlos nur noch grosse Skulpturen sind. Oder reglos stehend und liegend im Hafen von Lyon, auf dem Marktplatz von Brügge, zusammen mit 6999 in Barcelona oder das nächste Mal auf dem Bundesplatz in Bern. Vielleicht empfänden wir dabei eine neue Geborgenheit, wie wenn die kollektive Nacktheit uns eine neue Hülle verliehe. 